\title{
A novel case of compound heterozygous congenital hyperinsulinism without high insulin levels
}

\author{
Cassandra Brady ${ }^{1 *}$, Andrew A. Palladino $^{2}$ and Iris Gutmark-Little
}

\begin{abstract}
Background: Congenital hyperinsulinism leads to unregulated insulin secretion and hypoglycemia. Diagnosis can be difficult and genetic testing may be warranted.

Case: This patient initially presented at 11 months with seizure activity secondary to severe hypoglycemia. Her diagnostic evaluation included genetic studies, which confirmed congenital hyperinsulinism. A novel combination of mutations in the $A B C C 8$ gene leading to diffuse, diazoxide-unresponsive congenital hyperinsulinism was identified. Mutation analysis of ABCC8 showed three variants (R1215W - paternal, pathogenic; W739C - maternal, variant of unknown significance; R1393L - maternal, variant of unknown significance). Her clinical course continues to be complicated by severe, refractory hypoglycemia at age 3 years.

Conclusion: We describe a novel compound heterozygous mutation leading to diffuse, diazoxide-unresponsive congenital hyperinsulinism. This case illustrates challenges associated with diagnosing and managing congenital hyperinsulinism and the importance of genetic testing.
\end{abstract}

Keywords: Congenital hyperinsulinism, $A B C C 8$, Octreotide, Diazoxide-unresponsive

\section{Background}

Congenital hyperinsulinism (CHI) leads to hypoglycemia in infants and children due to inappropriately elevated insulin levels. Mutations leading to $\mathrm{CHI}$ have been described in nine genes [1]. The most common mutations occur in $A B C C 8$ and $K C N J 11$, which encode for the ATP-sensitive potassium $\left(\mathrm{K}_{\mathrm{ATP}}\right)$ channel present on the beta-cell plasma membrane. During normal glucose-stimulated insulin secretion, the $\mathrm{K}_{\mathrm{ATP}}$ channel closes in response to an increase in the energy potential of the beta-cell. Closure of this channel results in depolarization of the beta-cell plasma membrane leading to calcium influx into the beta-cell and insulin secretion. Certain mutations in $A B C C 8$ and $K C N J 11$ lead to defective $\mathrm{K}_{\text {ATP }}$ channels that are either unable to open or cannot localize to the plasma membrane [2]. Defective channels lead to continued depolarization of the plasma membrane and insulin secretion regardless of the plasma glucose level. Patients with these mutations

\footnotetext{
* Correspondence: cassie.brady@vanderbilt.edu

'Cincinnati Children's Hospital Medical Center, Division of Endocrinology,

3333 Burnet Ave, MLC 7012, Cincinnati, OH 45229, USA

Full list of author information is available at the end of the article
}

can be classified as diazoxide-responsive or unresponsive $[1,3]$. Diazoxide is a $K_{\text {ATP }}$ channel agonist which keeps the channel in an open state resulting in the suppression of insulin secretion [4]. Severe forms of CHI can lead to complete destruction of channel activity and are therefore unresponsive to diazoxide [2]. Inheritance of $A B C C 8$ and KCNJ11 mutations occurs in either a dominant or recessive fashion [1]. These mutations, dependent on inheritance pattern, may lead to focal or diffuse disease histologically (i.e. localized islet cell abnormalities versus effects throughout pancreas). Homozygous or compound heterozygous recessive mutations are associated with diffuse disease, and are typically managed medically or with near-total pancreatectomy, as indicated.

The diagnosis of $\mathrm{CHI}$ can be made during a fasting challenge. At the time of hypoglycemia (glucose $<50 \mathrm{mg} / \mathrm{dL}$ $(2.775 \mathrm{mmol} / \mathrm{L}))[2,3]$, a blood sample ("critical sample") is obtained to assess the presence or absence of key metabolic indices and counter-regulatory hormones which serve as alternative fuels and stimulants to raise serum glucose. Often, the fasting challenge does not yield confirmatory or clear diagnostic evidence of $\mathrm{CHI}$ and a repeat 
fasting evaluation may be necessary. Genetic testing is also recommended to assess for the common $\mathrm{CHI}$-causing mutations in patients with a known or suspected diagnosis of hyperinsulinism.

Once $\mathrm{CHI}$ is confirmed, defining the extent of disease is a critical next step to determine ideal intervention. Previously, imaging studies such as ultrasound, computed tomography, and magnetic resonance imaging have been implemented for the purpose of distinguishing focal from diffuse disease. However, these studies have not been shown to be effective for this purpose. The radiotracer ${ }^{18}$ fluoro-L- dihydroxyphenylalanine $\left({ }^{18} \mathrm{~F}-\mathrm{DOPA}\right)$, which concentrates in insulin-secreting beta cells of the pancreas, has been used in specialized CHI care centers for the past decade to classify disease. In the largest series, the specificity of this imaging technique to detect focal disease was $96 \%$ [5].

This case demonstrates a novel compound heterozygous mutation causing $\mathrm{CHI}$, the natural history of this mutation, and the associated challenges in management. This case also outlines the pitfalls of interpreting insulin levels at the time of hypoglycemia and emphasizes the importance of genetic testing in this setting.

\section{Case presentation}

An 11-month-old African-American female presented to neurology due to seizure-like activity. She was a former term infant with a birthweight of $3.714 \mathrm{~kg}$. At presentation she weighed $9.6 \mathrm{~kg}(56 \mathrm{th} \%)$ and was $77 \mathrm{~cm}$ (89th\%) tall. During her evaluation, a glucose value of $38 \mathrm{mg} / \mathrm{dL}$ $(1.998 \mathrm{mmol} / \mathrm{L})$ and bicarbonate of $24 \mathrm{mmol} / \mathrm{L}$ were noted.

During a subsequent fasting challenge, her serum glucose decreased to $32 \mathrm{mg} / \mathrm{dL}(1.776 \mathrm{mmol} / \mathrm{L})$ within $5.5 \mathrm{~h}$. The results of the critical sample are presented in Table 1. Specifically, her insulin level was appropriately low, while her beta-hydroxybutyrate (BOHB) was minimally elevated, and free fatty acids were inappropriately within the normal range. Additionally, her growth hormone was low. All other laboratory results including ammonia, "urine organic acids, "serum amino acids, and

Table 1 Fasting challenge results

\begin{tabular}{ll}
\hline Test name (Normal range) & $\begin{array}{l}\text { Laboratory } \\
\text { result }\end{array}$ \\
\hline $\begin{array}{l}\text { IGFBP-1 }(\mathrm{ng} / \mathrm{mL})(5-9 \text { years: } 15-95 ; \text { no reference range } \\
\text { for patients }<5 \text { years) }\end{array}$ & 61 \\
Insulin (<2-13 $\mu \mathrm{lU} / \mathrm{mL}$ fasting) & 0.2 \\
Glucose $(>70 \mathrm{mg} / \mathrm{dL} / 3.885 \mathrm{mmol} / \mathrm{L})$ & $32 / 1.776$ \\
C-peptide $(0.8-3.5 \mathrm{ng} / \mathrm{mL})$ & 0.5 \\
BOHB $(0-3.0 \mathrm{mg} / \mathrm{dL})$ & 4.3 \\
& $0.41 \mathrm{mmol} / \mathrm{L})$ \\
Free Fatty Acids $(0.5-0.9 \mathrm{mmol} / \mathrm{L})$ & 0.46 \\
Growth Hormone $(>7 \mathrm{ng} / \mathrm{mL})$ & 3 \\
\hline
\end{tabular}

*acylcarnitine profile were normal ("drawn in the fed state). A glucagon stimulation to assess glycemic response at the time of hypoglycemia was attempted but was unsuccessful. Based on the critical sample results, she was thought to have growth hormone deficiency and was started on growth hormone therapy. She was discharged after several inpatient days with improved glucose levels.

In the interim, the insulin-like growth factor-1 (IGF-1) (prior to growth hormone therapy) resulted at $105.7 \mathrm{ng} / \mathrm{mL}$ (approximately the 80th\% for age and sex), and insulinlike growth factor binding protein-3 (IGFBP-3) was $2800 \mathrm{ng} / \mathrm{mL}$ (above the mean for age and sex). While at home, she was noted to have a glucose of $19 \mathrm{mg} / \mathrm{dL}$ $(1.0545 \mathrm{mmol} / \mathrm{L})$ despite growth hormone therapy. Given the severity of her hypoglycemia, she was readmitted for further assessment. An arginine/clonidine growth hormone stimulation test done after discontinuation of growth hormone revealed a peak growth hormone level of $7.9 \mathrm{ng} / \mathrm{dL}$ (radioimmunoassay). In the setting of continued hypoglycemia despite growth hormone therapy, her critical sample obtained at her initial admission was reviewed and determined to be concerning for $\mathrm{CHI}$. Therefore genetic studies for $\mathrm{CHI}$ were sent (Athena Diagnostics, Worcester, Massachusetts).

While genetic studies were pending, diazoxide treatment was initiated and titrated to $15 \mathrm{mg} / \mathrm{kg} /$ day divided three times daily. However, she continued to have hypoglycemia. After one week of diazoxide therapy, octreotide was added. Octreotide was increased to 15 $\mathrm{mcg} / \mathrm{kg} /$ day, with subsequent improvement but not resolution of hypoglycemia. Frequent feeds and uncooked cornstarch were implemented to avert hypoglycemia. Her hyperinsulinism was deemed diazoxide-unresponsive and diazoxide was discontinued.

Mutational analysis confirmed a diagnosis of $\mathrm{CHI}$ as three variants in $A B C C 8$ were identified (Table 2). The R1215W variant was found to be paternally-inherited while the W739C and R1393L variants were maternally inherited. The paternal change was a known mutation described previously (at Children's Hospital of Philadelphia) in a patient with diffuse disease. In this previously described patient, the inheritance pattern was thought to be recessive, given a normal maternal $A B C C 8$ gene copy. In our patient, the significance of the maternal variants was unclear as they had not been previously described in

Table 2 Genetic results (ABCC8 Mutation)

\begin{tabular}{lll}
\hline Mutation & Inheritance & Interpretation \\
\hline c. R1215W & Paternal & Pathogenic \\
c. W739C & Maternal & VUS \\
c. R1393L & Maternal & VUS \\
\hline
\end{tabular}

VUS variant of unknown significance 
$\mathrm{CHI}$ cases. Therefore, for our patient, we were unable to predict focal versus diffuse disease pathology based on mutational analysis alone.

Our patient was transferred to Children's Hospital of Philadelphia for an 18-fluoro L-3, 4-dihydroxyphenylalanine positron emission tomography $\left({ }^{18}\right.$-F-DOPA-PET) scan. There was no focal uptake of isotope by the pancreas (Fig. 1), which suggested, but did not confirm diffuse disease. A pancreatic biopsy was subsequently recommended in order to further delineate her pathology, but was declined by the family. A gastrostomy tube was placed for enteral dextrose administration (overnight glucose infusion rate (GIR) of $7 \mathrm{mg} / \mathrm{kg} / \mathrm{min}$ ).

Over several months, the child has continued to have intermittent, daily hypoglycemia despite adjustments of her treatment regimen. The GIR of her fluids has been gradually increased. Her current treatment regimen at age 3 years consists of octreotide 20 $\mathrm{mcg} / \mathrm{kg} /$ day divided three times daily and overnight dextrose (14 h, GIR of $9 \mathrm{mg} / \mathrm{kg} / \mathrm{min})$ through her gastrostomy tube. She continues to have daytime hypoglycemia [glucose $<70 \mathrm{mg} / \mathrm{dL}(3.885 \mathrm{mmol} / \mathrm{L})$ ]. Speech delay that was noted shortly after diagnosis persists despite therapy. Considering her disease and failure of medical management, a near-total pancreatectomy may be necessary to achieve normal blood glucose levels. Other treatment options that are also being considered include continuous glucagon via an insulin pump $[6,7]$ and continuous octreotide via an insulin pump [8]. These treatments have not been pursued based on parental requests.

\section{Conclusions}

This case reveals a new compound heterozygous mutation in $A B C C 8$ that leads to diffuse, diazoxide-unresponsive $\mathrm{CHI}$. It highlights the severity of disease due to this combination of mutations and the difficulty of diagnosis and management.

To diagnose CHI, laboratory tests known as the "critical sample", are utilized and include: plasma glucose, plasma insulin, c-peptide, insulin-like growth factor binding protein-1 (IGFBP-1), BOHB, free fatty acids, ammonia, lactate, pyruvate, acylcarnitine profile, free and total carnitine, organic acids (urine), growth hormone, and cortisol [3]. The diagnosis of CHI can be made in the setting of hypoglycemia when elevated insulin levels are present with suppression of $\mathrm{BOHB}$ and free fatty acids. Often, the initial fasting challenge does not yield confirmatory or clear diagnostic evidence of $\mathrm{CHI}$ and repeat fasting evaluations may be necessary.

In the critical sample, insulin and c-peptide levels help to establish the presence of inappropriate elevations in insulin and to distinguish between excess endogenous and exogenous insulin, respectively. Interpretation of insulin levels at the time of hypoglycemia can be difficult, as evidenced by this case. Insulin levels may be elevated, decreased, or normal [9]. This may be due to periodic release of insulin [3], insulin degrading enzymes in hemolyzed blood samples [9-11], insulin antibodies [12], and rapid hepatic clearance [9, 13]. At room temperature, research shows that $>90 \%$ of insulin can be degraded due to massive hemolysis which induces degrading enzymes [11]. Maintaining the

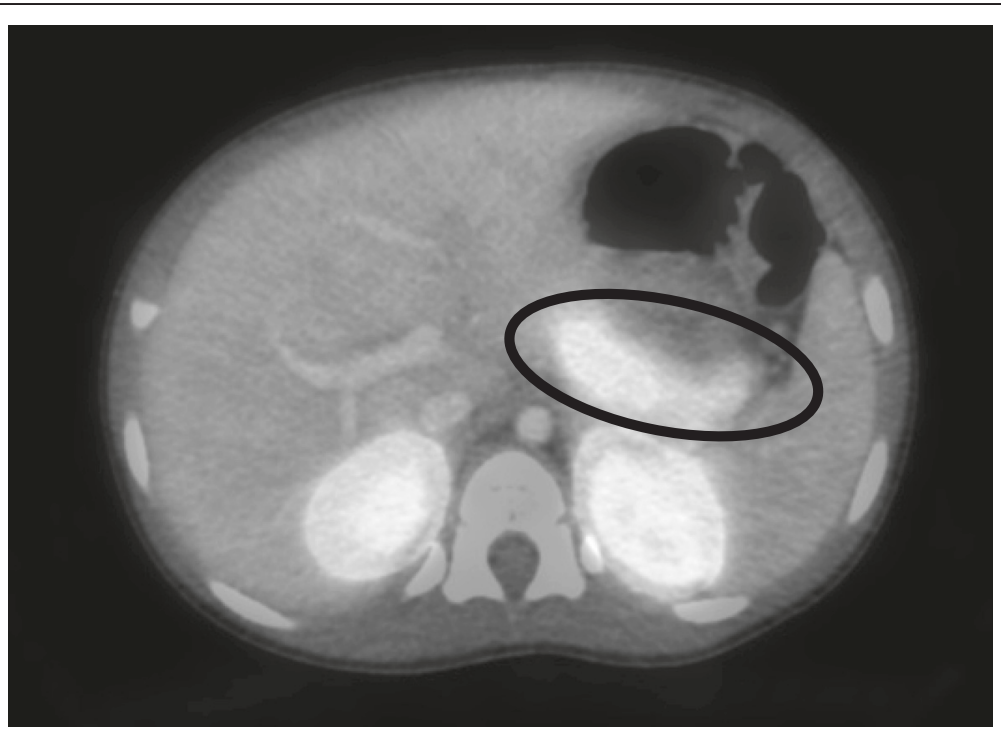

Fig. 1 Results of F-Dopa PET Scan. This image demonstrates the results of our patient's ${ }^{F}$-Dopa PET scan. The pancreas is circled in black. There is no evidence of focal tracer uptake on this image, suggesting diffuse disease. However the finding of diffuse uptake on F-Dopa PET scan does not exclude a focal lesion 
sample at colder temperatures $\left(4^{\circ} \mathrm{C}\right)$ may decrease degrading enzyme activity [11], however this can make critical sample collection more difficult. Interfering insulin antibodies may also lead to falsely low insulin levels as demonstrated in immunoradiometric assays and electrochemiluminescent assays in prior reports [12]. Insulin is also rapidly degraded by the body at a rate of 2 percent per minute with about $50 \%$ removed by the liver $[13,9]$. These issues may have played a role in our patient's decreased insulin level on her fasting challenge.

Another important indicator of hyperinsulinism is the glycemic response to glucagon at the time of hypoglycemia [14]. A glucose rise after glucagon of greater than $30 \mathrm{mg} / \mathrm{dL}(1.665 \mathrm{mmol} / \mathrm{L})$ may reflect hyperinsulinism with a sensitivity of $91 \%$ and specificity of $93 \%[14,9]$. This glycemic excursion after glucagon reflects the suppressive effects of insulin on the release of glycogen stores from the liver. In our patient's evaluation, the glucagon challenge was not completed in a way that it would have been interpretable.

The fasting challenge is an important opportunity to obtain and interpret other counter-regulatory mechanisms that maintain euglycemia. Elevation in $\mathrm{BOHB}$ is a measure of appropriate ketogenesis during fasting. $\mathrm{BOHB}$ values less than $2.7 \mathrm{mmol} /$ liter $(28.1 \mathrm{mg} / \mathrm{dL})$ during hypoglycemia have a reported sensitivity and specificity of $100 \%$ in hyperinsulinemia induced by an insulinoma $[9,15]$. The patient in this case had a relatively low $\mathrm{BOHB}$ value, which may have been an indicator of high insulin levels. Growth hormone and cortisol act as counter-regulatory hormones to increase lipolysis and gluconeogenesis, respectively. Growth hormone and cortisol are expected to be increased during hypoglycemia if these hormonal systems are intact [16]. The child in this case was started on growth hormone due to the low value at the time of hypoglycemia. However, decreased growth hormone and cortisol levels at the time of hypoglycemia are not diagnostic of deficiencies, and $65 \%$ of children in a study by Kelly et al. were misdiagnosed with growth hormone deficiency during a fasting challenge [17]. Our patient subsequently had a normal growth hormone response during further evaluation.

Shortly after diagnosis in our patient's clinical course, it became evident that the $\mathrm{CHI}$ was likely diazoxideunresponsive. Diazoxide-unresponsive $\mathrm{CHI}$ is typically due to defects in the $K_{\text {ATP }}$ channel [18]. However genetic analysis and determination of inheritance pattern is extremely helpful for both prediction of disease pathology and response to therapy. Inheritance of $A B C C 8$ and KCNJ11 mutations occurs in either a dominant or recessive fashion [1]. Further, depending on inheritance pattern, these mutations may lead to focal or diffuse disease histologically. Autosomal recessive mutations from both parents typically cause diffuse disease. A paternally-inherited recessive mutation in the $\mathrm{K}_{\mathrm{ATP}}$ channel with maternal loss of heterozygosity leads to paternal uniparental disomy and the development of focal disease $[3,1]$. The genetic results for this patient demonstrated a paternally-inherited known pathogenic recessive mutation, but the pathogenicity of the maternal mutations was unclear. We have recently learned (from a patient at Children's Hospital of Philadelphia) that the W739C maternal variant has been identified in a patient with diffuse disease indicating that it likely acts recessively. We suspect the R1393L variant is pathogenic and could act either recessively or dominantly. Of note, our patient's brother is a carrier of the paternal mutation, but did not inherit either of the maternal mutations. Both of her parents and her brother have no signs or symptoms of hypoglycemia.

An ${ }^{18}$-F-Dopa-PET scan was obtained. This noninvasive imaging technique has been used to further delineate between focal and diffuse CHI [19]. However, diffuse uptake on this scan does not rule out focal disease [3]. In the largest series, the specificity of this imaging technique to detect focal disease was $96 \%$, with a positive predictive value of $96 \%$. In this series, 105 patients with confirmed $\mathrm{CHI}$ underwent pancreatectomy. Of these, 53 had a postoperative diagnosis of focal CHI. However, preoperative ${ }^{18}$-F-Dopa-PET imaging in 8 of these 53 was reported erroneously as diffuse [5].

Finally, there are reports of clinical improvement in individuals with heterozygous $A B C C 8$ mutations [20] or those with severe disease [21] with time. Whether improvement will occur in this patient, remains to be determined, but is becoming less likely. We speculate that the late presentation of this patient is more likely due to late detection as opposed to the genetic mutations.

We describe a novel compound heterozygous mutation leading to diffuse, diazoxide-unresponsive $\mathrm{CHI}$. This case illustrates the pitfalls and challenges associated with diagnosing $\mathrm{CHI}$ and the importance of genetic testing and how it can guide management decisions, including whether or not imaging studies are warranted. Lastly, the case illustrates the difficulty of medically-managing a patient with diffuse $\mathrm{CHI}$.

\section{Consent}

Written informed consent was obtained from the patient for publication of this case report and any accompanying images. A copy of the written consent is available for review by the Editor-in-Chief of this journal.

\section{Abbreviations}

CHI: Congenital hyperinsulinism; $\mathrm{K}_{\text {ATP: }}$ ATP-sensitive potassium; IGF-1: Insulin-like growth factor-1; IGFBP-3: Insulin-like growth factor binding protein-3; IGFBP-1: Insulin-like growth factor binding protein-1; BOHB: beta-hydroxybutyrate; GIR: Glucose infusion rate; ${ }^{18}$-F-DOPA-PET: 18 -fluoro L-3,4-dihydroxyphenylalanine positron emission tomography; ${ }^{18}$-F-DOPA: 18-fluoro L-3,4-dihydroxyphenylalanine. 


\section{Competing interests}

The authors declare that they have no competing interests.

\section{Authors' contributions}

CB and IL provided initial care for patient at home institution and continue to provide care to patient. AP provided subsequent care of patient at Children's Hospital of Philadelphia and interpreted genetic results and imaging. CB drafted the manuscript. AP and IL provided edits to manuscript. All authors read and approved final version of manuscript.

\section{Acknowledgements}

We thank Lisa J. States for her input regarding the F-Dopa PET scan and Kara Boodhansingh for her guidance in genetic interpretation.

\section{Author details}

${ }^{1}$ Cincinnati Children's Hospital Medical Center, Division of Endocrinology, 3333 Burnet Ave, MLC 7012, Cincinnati, OH 45229, USA. ${ }^{2}$ Children's Hospital of Philadelphia, Division of Endocrinology, 34th Street and Civic Center Boulevard, Philadelphia, PA 19104, USA.

Received: 6 April 2015 Accepted: 1 July 2015

Published online: 15 July 2015

\section{References}

1. Snider KE, Becker S, Boyajian L, Shyng SL, MacMullen C, Hughes N, et al. Genotype and phenotype correlations in 417 children with congenital hyperinsulinism. J Clin Endocrinol Metab. 2013;98:E355-63.

2. Palladino AA, Stanley CA. A specialized team approach to diagnosis and medical versus surgical treatment of infants with congenital hyperinsulinism. Semin Pediatr Surg. 2011;20:32-7.

3. Palladino AA, Bennett MJ, Stanley CA. Hyperinsulinism in infancy and childhood: when an insulin level is not always enough. Clin Chem. 2008;54:256-63.

4. Sarafoglou K, Hoffman G. Pediatric endocrinology and inborn errors of metabolism. New York: McGraw-Hill Medical; 2009.

5. Laje P, States $\sqcup$, Zhuang H, Becker SA, Palladino AA, Stanley CA, et al. Accuracy of PET/CT Scan in the diagnosis of the focal form of congenital hyperinsulinism. J Pediatr Surg. 2013;48:388-93.

6. Neylon OM, Moran MM, Pellicano A, Nightingale M, O'Connell MA. Successful subcutaneous glucagon use for persistent hypoglycaemia in congenital hyperinsulinism. J Pediatr Endocrinol Metab. 2013;26:1157-61.

7. Mohnike K, Blankenstein O, Pfuetzner A, Potzsch S, Schober E, Steiner S, et al. Long-term non-surgical therapy of severe persistent congenital hyperinsulinism with glucagon. Horm Res. 2008;70:59-64.

8. Yorifuji T, Kawakita R, Hosokawa Y, Fujimaru R, Matsubara K, Aizu K, et al. Efficacy and safety of long-term, continuous subcutaneous octreotide infusion for patients with different subtypes of KATP-channel hyperinsulinism. Clin Endocrinol (Oxf). 2013;78:891-7.

9. De Leon DD, Stanley CA. Determination of insulin for the diagnosis of hyperinsulinemic hypoglycemia. Best Pract Res Clin Endocrinol Metab. 2013;27:763-9.

10. Cantrell JW, Hochholzer JM, Frings CS. Effect of hemolysis on the apparent concentration of insulin in plasma. Clin Chem. 1972;18:1423-5.

11. Chevenne D, Letailleur A, Trivin F, Porquet D. Effect of hemolysis on the concentration of insulin in serum determined by RIA and IRMA. Clin Chem. 1998:44:354-6.

12. Sapin R. The interference of insulin antibodies in insulin immunometric assays. Clin Chem Lab Med. 2002;40:705-8.

13. Berson SA, Yalow RS, Bauman A, Rothschild MA, Newerly K. Insulin-I131 metabolism in human subjects: demonstration of insulin binding globulin in the circulation of insulin treated subjects. J Clin Invest. 1956;35:170-90.

14. Finegold DN, Stanley CA, Baker L. Glycemic response to glucagon during fasting hypoglycemia: an aid in the diagnosis of hyperinsulinism. J Pediatr. 1980;96:257-9.

15. Placzkowski KA, Vella A, Thompson GB, Grant CS, Reading CC, Charboneau $\mathrm{JW}$, et al. Secular trends in the presentation and management of functioning insulinoma at the Mayo Clinic, 1987-2007. J Clin Endocrinol Metab. 2009;94:1069-73.

16. Sperling M. Pediatric endocrinology. Fourthth ed. Philadelphia, PA: Elsevier Saunders; 2014.
17. Kelly A, Tang R, Becker S, Stanley CA. Poor specificity of low growth hormone and cortisol levels during fasting hypoglycemia for the diagnoses of growth hormone deficiency and adrenal insufficiency. Pediatrics. 2008;122:e522-8.

18. Flanagan S, Damhuis A, Banerjee I, Rokicki D, Jefferies C, Kapoor R, et al. Partial ABCC8 gene deletion mutations causing diazoxide-unresponsive hyperinsulinaemic hypoglycaemia. Pediatr Diabetes. 2012;13:285-9.

19. Ribeiro MJ, De Lonlay P, Delzescaux T, Boddaert N, Jaubert F, Bourgeois S, et al. Characterization of hyperinsulinism in infancy assessed with PET and 18 F-fluoro-L-DOPA. J Nucl Med. 2005;46:560-6.

20. Kapoor RR, Flanagan SE, Arya VB, Shield JP, Ellard S, Hussain K. Clinical and molecular characterisation of 300 patients with congenital hyperinsulinism. Eur J Endocrinol. 2013;168:557-64.

21. Aynsley-Green A, Hussain K, Hall J, Saudubray JM, Nihoul-Fekete C, De Lonlay-Debeney $\mathrm{P}$, et al. Practical management of hyperinsulinism in infancy. Arch Dis Child Fetal Neonatal Ed. 2000;82:F98-107.

\section{Submit your next manuscript to BioMed Central and take full advantage of:}

- Convenient online submission

- Thorough peer review

- No space constraints or color figure charges

- Immediate publication on acceptance

- Inclusion in PubMed, CAS, Scopus and Google Scholar

- Research which is freely available for redistribution 